\title{
Pedagogia Crítica da Educação Física no Jogo das Relações de Poder ${ }^{1}$
}

Felipe Quintão de Almeida*

Ao mestre, Valter Bracht, com carinho.

Resumo: Este artigo insere-se em uma pesquisa sobre os fundamentos da pedagogia crítica da educação física. Elege como interlocutor da análise os escritos do filósofo Michel Foucault, investigando a reordenação efetuada pelo autor em sua discussão sobre a noção de (relações de) poder e sujeito no último domínio de sua obra. Busca compreender os corolários desse deslocamento nos impulsos emancipadores e libertadores da pedagogia crítica em nossa área. Aponta a premência de seguir problematizando, autocriticamente, sua própria atualidade discursiva no presente.

Palavras-chave: Educação Física. Poder. Controles infor-

mais da sociedade. Michel Foucault.

\section{INTRODUÇÃO}

\begin{abstract}
Existem momentos na vida onde a questão de saber se se pode pensar diferentemente do que se pensa, e perceber diferentemente do que se vê, é indispensável para continuar a olhar ou a refletir (FOUCAULT, 1997b, p. 13).
\end{abstract}

O campo do que designamos de pedagogia crítica tornou-se muito mais matizado na última década, abrigando uma pluralidade de perspectivas teóricas e políticas que puseram um fim à homogeneidade epistemológica e, conseqüentemente, política nele presente a partir dos idos de 1980, momento em que uma determina-

\footnotetext{
Agradecemos as leituras críticas e muito amigáveis de Alexandre Fernandez Vaz, Ivan Marcelo Gomes e Valter Bracht. Gratos também ao parecerista anônimo que fez algumas sugestões na escrita.

*Membro do laboratório de Estudos em Educação Física (LESEF/CEFD/UFES) e do Núcleo de Estudos e Pesquisas Educação e Sociedade Contemporânea (CED/UFSC). Doutorando em educação no PPGE/CED/UFSC. E-mail: fqalmeida@hotmail.com
}

Movimento, Porto Alegre, v.12, n. 03, p. 141-164, setembro/dezembro de 2006. 
da concepção do marxismo (pedagógico), à semelhança do que acontecia no campo educacional mais amplo, conquistou sua hegemonia no âmbito das perspectivas críticas em educação física.

Essa nova agenda teórico-política introduziu um elemento de tensão no cerne da pedagogia crítica da educação física, desalojandoa de sua confortável posição de vanguarda e colocando-a em incômoda defensiva. Em alguns casos, isso desencadeou uma genealogia da educação física crítica (NOGUEIRA, 2004) e em outros significou dar o adeus à educação física progressista (LIMA, 1997a). Longe de caracterizar essa diferenciação discursiva como o resultado do avanço de forças conservadoras no âmago da tradição crítica em educação física ${ }^{2}$ preferimos vislumbrar a existência de um novo estágio na teoria pedagógica crítica, momento em que o controvertido diálogo entre críticos e pós-críticos (algumas vezes reproduzido pelo binarismo modernos/pós-modernos) domina a atual etapa dessa tradição, desencadeando uma autocrítica de seus alicerces - daí a sensação de crise que a acompanha nesses últimos anos.

Com a pedagogia crítica, mas, também contra ela - eis o momento em que a ambivalência que a caracteriza no presente se revela sem disfarces -, neste artigo damos prosseguimento aos esforços de Bracht e Almeida (2006) ao efetuarem uma autocrítica dos fundamentos da pedagogia crítica da educação física e das celeumas desencadeadas por sua crise em função da presença da dúvida pósmoderna na área educacional. À diferença daquele trabalho, todavia, isso será feito aqui se recorrendo aos escritos tardios ${ }^{3}$ do impor-

2 Posição assumida por Moraes (2004) no que diz respeito ao campo educacional mais amplo (com repercussões, é claro, na educação física).

${ }^{3}$ Mesmo estabelecendo esse recorte na obra de Foucault, temos clareza dos riscos de se fazê-lo em um filósofo que se destacou por rejeitar rótulos e esquemas de pensamento. Ao invés de fases ou períodos bem demarcados em seu trabalho, inclinamo-nos a pensar que, tal como uma espiral hermenêutica (GROS, 2004), elas se incorporam e se atravessam, alargando as problematizações e as maneiras de trabalhá-las. Sem perder de vista essa dinâmica, podemos situar o último domínio foucaultiano (VEIGA-NETO, 2003) nas entrevistas, conferências e cursos realizados a partir do final dos anos 1970 e que culminou com a publicação, no ano de sua morte, dos volumes II e III da História da sexualidade (1997b, 1997c).

Movimento, Porto Alegre, v.12, n. 03, p. 141-164, setembro/dezembro de 2006. 
tante filósofo francês Michel Foucault. Interessa-nos investigar uma inflexão em seu trabalho que, segundo pensamos, tem sido pouco explorada na educação física: trata-se da reordenação na discussão sobre o poder, suas relações e o sujeito em seus últimos escritos, o que, como veremos alhures nesse artigo, trará nevrálgicas implicações ao discurso emancipador e libertador da pedagogia crítica da educação física, especialmente se considerarmos o comprometimento desta com relações de poder que estão envolvidas em toda agência pedagógica, tal como tem sido alertado por aquelas perspectivas pós-críticas ${ }^{4}$ do campo educacional.

Iniciaremos nossa autocrítica de modo a apresentar, no tópico inicial, o deslocamento efetuado na analítica de poder foucaultiana: de uma análise das relações de poder centrada prioritariamente em suas técnicas e táticas de dominação para sua compreensão como tecnologia de governo, possibilitando, com isso, o surgimento de um si mesmo constituído ética-esteticamente.

\section{ENTRE A OBJETIVAÇÃO EA PRÁTICA DA LIBERDADE: RELAÇÕES DE PODER E O GOVERNO DE SI NO ÚLTIMO DOMÍNIO FOUCAULTIANO}

Nos estudos de Foucault sobre a entrada da vida na história (no campo de uma tecnologia política dos indivíduos), os processos da vida foram levados em conta por ele enfatizando-se os procedimentos de poder e de saber que objetivavam, em sua produtividade, controlá-los e modificá-los. Foucault demonstrou que foi exatamente em torno dos cuidados com a vida da população que se produziu uma arte de táticas e técnicas que, encontrando no Estado um novo suporte e um princípio de transformação, se desenvolveu a partir da incorporação, difusão e multiplicação das tradicionais técnicas do que ele chama de poder pastoral. A im-

${ }^{4}$ Um mapa configuracional da pedagogia pós-crítica no Brasil pode ser obtido em Paraíso (2004).

Movimento, Porto Alegre, v.12, n. 03, p. 141-164, setembro/dezembro de 2006. 
plantação das individualizantes técnicas pastorais no quadro do laico aparelho de Estado é, para Foucault, a matriz da razão política moderna. A biopolítica das populações tornar-se-ia para ele o objeto do qual a governamentalidade deveria ter em conta em suas observações para chegar a governar de modo racional e refletido.

O caráter governamental que o Estado moderno assumia, sua governamentalização, fez do indivíduo e sua espécie uma aposta essencial para o poder e as relações desencadeadas por seu exercício. O governo não era uma simples instrumentalização da força do Estado, mas mais bem compreendido como uma centralização e/ou racionalização, historicamente definida, das relações de poder. Desenvolveu-se então um conjunto de procedimentos, saberes, instituições e táticas com o intuito de se permitir o exercício dessa forma específica de poder que tem como meta o governo biopolítico da população, de tal maneira que seu desenvolvimento reforçaria ao mesmo tempo a potência do Estado e sua vida. Não à toa que o sujeito foi aí pensado como o produto objetivo dessa governamentalização das relações de poder com o recurso a sistemas de saber/poder cada vez mais sofisticados e complexos. Neste bojo, uma anátomo-política do corpo humano, em instituições como a escola, o exército, as oficinas, as prisões, os hospitais, os ateliês etc., sua disciplina afinal, tornou-se ainda mais valorizada a partir do momento em que gerir a vida da população tornou-se tarefa de uma razão de Estado. Os procedimentos de individualização e de totalização daí decorrentes seriam o resultado histórico de uma racionalidade política centrada no poder sobre a vida, na era que seria para Foucault a do biopoder (FOUCAULT, 1997a, 1999a, 2003, 2004a).

Compreende-se por que sua analítica do poder é rica em descrições das práticas divisórias e dos procedimentos estratégicos postos em jogo pelos poderes políticos hegemônicos e suas maquinarias, evidenciando ainda sua predileção pela descrição minuciosa de grandes estruturas de dominação ou das instituições a elas agenciadas. Nesses casos, o poder se exerceria sobre cada

Movimento, Porto Alegre, v.12, n. 03, p. 141-164, setembro/dezembro de 2006. 
indivíduo, impondo-o uma determinada identidade e controlando a espécie conforme um determinado modo de (des)subjetivação. A análise foucaultiana tratava de destacar a dimensão fundamentalmente dominadora da prática de governo e sua racionalidade política, já que sua pesquisa incidia, em sua crítica genealógica, “[...] sobre as técnicas do poder, sobre a tecnologia do poder. Ela consiste em estudar como o poder domina e se faz obedecer" (FOUCAULT, 2003, p. 267).

Para isso, Foucault elaborou, já a partir de Vigiar e Punir: história da violência nas prisões, uma concepção nominalista de poder, afastando-se do modelo jurídico da soberania, dos aparelhos de Estado e das ideologias que o acompanham, uma vez que acreditava que as análises do poder orientadas ascendentemente (sob o espectro de uma microfísica do poder, portanto) deveriam centrar-se nos âmbitos da dominação, dos operadores materiais, das formas de sujeição, das conexões e utilizações dos sistemas locais dessa sujeição. Em suma, tratava-se de analisar o poder a partir das técnicas e táticas de dominação, cada vez mais gerais e globais. Eis a linha que Foucault tentou seguir nas diferentes pesquisas sobre o poder psiquiátrico, o sistema penal, a sexualidade infantil etc. Era para ele o caso de partir da própria relação de dominação no que ela tem de factual, de efetivo, e de ver como é essa própria relação que determina os elementos sobre os quais ela incide. Portanto, Foucault (1999a, p. 52) adotou " [...] o ponto de vista tríplice das técnicas, da heterogeneidade das técnicas e de seus efeitos de sujeição, que fazem dos procedimentos de dominação a trama efetiva das relações de poder e dos grandes aparelhos de poder". Para compreendê-los, devia-se considerar o quão produtivo é o poder: tanto o indivíduo quanto o conhecimento que dele se pode ter se originam dessa produção, eis aí sua positividade".(FOUCAULT, 1992, 1993).

Essa analítica do poder foucaultiana, que se tornou bastante conhecida entre nós da educação física, acaba soando como sendo algo bastante fatalista e determinista em função da insistência do

Movimento, Porto Alegre, v.12, n. 03, p. 141-164, setembro/dezembro de 2006. 
autor, "[...] quando estudava os hospícios, as prisões etc., nas técnicas de dominação" (FOUCAULT, 2004a, p. 95), estratégia que deixou pouco espaço para que fossem concebidas ações humanas significativas dirigidas à obtenção da liberdade. O próprio Foucault (2004a) admitiu que em livros como Vigiar e punir: história da violência nas prisões, História da loucura e As palavras e as coisas, o que o incomodava, passado alguns anos após serem escritos, era o fato de ter considerado as experiências do poder e da produção da verdade sem levar em conta a experiência da conduta individual.

Esse quadro, amplamente veiculado e que serviu de base para uma crítica da crítica em educação física, sofre uma alteração importante no último domínio foucaultiano (LAZZARATO, 2000; GROS, 2004). Segundo a autocrítica foucaultiana (2004a, p. 285), "Eu mesmo não tenho certeza, quando comecei a me interessar por esse problema do poder, de ter falado dele muito claramente nem de ter empregado as palavras adequadas. Tenho, agora, uma visão muito mais clara de tudo isso". O que se torna central são os combates e as lutas inerentes às relações de poder, não mais a descrição das enormes articulações institucionais e políticas que formam as estruturas de poder. Doravante, Foucault interrogará o poder, seus dispositivos e suas práticas, não a partir de uma teoria da obediência e suas formas de legitimação, já que esse tipo de análise não vale mais para ele como uma analítica de qualquer relação de poder possível, mas sim a partir da capacidade de transformação que todo exercício de poder implica, quer dizer, uma "[...] multiplicidade de correlações de forças imanentes ao domínio onde se exercem e constitutivas de sua organização; o jogo que, através de lutas e afrontamentos incessantes as transforma, reforça, inverte [...]" (FOUCAULT, 1997a, p. 88).

Essas correlações de forças, certamente uma herança nietzschiana, são guerras anárquicas de desestabilização infinita dos mecanismos de poder: são relações antagonistas, de estratégias, de enfretamento, de combate. Como então esta nova ontologia

Movimento, Porto Alegre, v.12, n. 03, p. 141-164, setembro/dezembro de 2006. 
das forças poderia dar lugar a processos de constituição políticos inéditos e a processos de subjetivação independentes? Conforme a interpretação de Lazzarato (2000) e Ortega (1999) é em resposta a essas questões que Foucault desenvolve a passagem do modelo da guerra ao modelo do governo na análise das relações de poder. É por isso que proporá o termo conduta como aquele que mais bem capta o que há de específico nas relações de poder. A conduta pode ser caracterizada pela maneira de conduzir os outros bem como a maneira de se conduzir a si mesmo. Esta arte de conduzir os outros e a si próprio faz das relações de poder muito menos da ordem do afrontamento entre dois adversários (como na guerra) ou do vínculo de um com relação ao outro, do que da ordem do governo. O modo de relação próprio ao poder "[...] não deveria, portanto, ser buscado do lado da violência e da luta, nem do lado do contrato e da aliança voluntária (que não podem ser mais do que instrumentos); porém, do lado deste modo de ação singular - nem guerreiro nem jurídico - que é o governo" (FOUCAULT, 1995, p. 244).

O traço distintivo do poder seria o fato de que alguns homens, sem recorrer à coerção ou à repressão, podem determinar o governo de outros homens. Governar seria assim a estruturação do eventual campo de ação dos outros: um modo de ação sobre ações. Definida como ação sobre outros e a si próprio, Foucault atrela no coração mesmo de toda relação de poder a liberdade. O poder só se exerce em sujeitos potencialmente livres e enquanto estes permanecerem livres. Não há qualquer relação de confronto e exclusão entre poder e liberdade, mas um jogo mais complexo no qual:

[...] a liberdade aparecerá como condição de existência do poder (ao mesmo tempo sua precondição, uma vez que é necessário que haja liberdade para que o poder se exerça, e também seu suporte permanente, uma vez que se ela se abstraisse inteiramente do poder que sobre ela se exerce, por isso mesmo desapareceria, e deveria buscar um substituto na coerção pura e simples da violência); porém, ela

Movimento, Porto Alegre, v.12, n. 03, p. 141-164, setembro/dezembro de 2006. 
aparece também como aquilo que só poderá se opor a um exercicio de poder que tende, enfim, a determiná-la inteiramente (FOUCAULT, 1995, p. 244).

Com estas reordenações na noção de poder, não é mais possível imputar a Foucault, como normalmente se costuma(va) fazer, a idéia de que o poder é um sistema de dominação que controla tudo e que não deixa espaço para a liberdade, já que no centro da relação de poder, provocando-a, encontra-se a liberdade. Mesmo naquelas situações nas quais a relação de poder é completamente desequilibrada, “[...] um poder só se exerce sobre outro à medida que ainda reste a esse último a possibilidade de se matar, de pular pela janela ou de matar o outro" (FOUCAULT, 2004a, p. 277). Só assim o outro poderia ser concebido e mantido até o fim como sujeito da ação, como sujeito ativo que é capaz de influenciar a conduta do outro (FOUCAULT, 1995).

Compreendido assim, temos que admitir nessa fórmula geral das relações de poder que não há poder sem recusa ou desacordo em potencial. Aqui já não existem mais relações de poder que sejam completamente triunfantes e que a dominação seja incontornável. Isso significa que onde aquelas relações existirem haverá decerto resistência, já que se não houvesse possibilidade alguma dela, relações de poder não estariam em jogo. Elas não podem existir senão em função de uma multiplicidade de pontos de resistência que se apresentam como o outro da relação de poder, inscrevendo-se nestas relações como interlocutores irredutíveis.

Essa relação de incitação recíproca cessa de acontecer quando os ambíguos e móveis jogos das relações de poder são substituídos pelos estáveis estados de dominação. Embora estes sejam instrumentos e efeitos daquelas relações, não constituem para Foucault seu princípio ou sua natureza. Ao contrário, quando um sujeito está completamente a disposição do outro e se torna o objeto sobre o qual exerce uma conduta constante e com suficiente certeza a ponto de produzir uma ilimitada servidão voluntária -

Movimento, Porto Alegre, v.12, n. 03, p. 141-164, setembro/dezembro de 2006. 
como no caso da escravidão -, não há qualquer sinal de relações de poder. Um homem acorrentado e pisado está submetido à força que se exerce sobre ele, mas não ao poder (FOUCAULT, 2003). Em tais condições, as práticas de liberdade e a resistência deixam de existir ou então se apresentam como extremamente restritas. É preciso, pois, pôr um limite aos excessos do exercício de poder que podem levar aos estados de dominação, caracterizados que são pelo bloqueio ou cristalização da móvel e estratégica arte do governo, quer dizer, aquele modo de ação sobre ação que pode conduzir à liberdade.

Com o deslocamento operado por Foucault no conceito de poder, a análise da governamentalidade, tanto prática como teoricamente, não pode prescindir mais do sujeito definido pela relação de si para consigo e também em função de sua conduta com os outros (FOUCAULT, 2004a). De acordo com Senelart (1995), essa reordenação, pela qual Foucault rompe com certos aspectos de seu pensamento dos anos de 1970, tem seu corolário na ética do cuidado de si como prática refletida da liberdade, tema recorrente de seus últimos trabalhos em vida. É por isso que ele, "Tendo estudado o campo do poder tomando como ponto de partida as técnicas de dominação, gostaria de estudar, durante os próximos anos, as relações de poder partindo das técnicas de si" (FOUCAULT, 2004a, p. 95). Esse é o momento em que um complexo conjunto de práticas de subjetivação ou tecnologias do eu, distintas substancialmente da objetivação característica das tecnologias disciplinares, torna-se a preocupação central de Foucault: "[...] como constituímos diretamente nossa identidade por meio de certas técnicas éticas de si, que se desenvolveram desde a Antiguidade até nossos dias?" (FOUCAULT, 2004a, p. 302).

Se o sujeito não se constitui única e exclusivamente através de práticas de sujeição, mas também através de práticas mais autônomas de liberação, sua genealogia na civilização ocidental precisa considerar não apenas as técnicas de dominação, mas também as técnicas de si. Não é outro o motivo para que Foucault em A

Movimento, Porto Alegre, v.12, n. 03, p. 141-164, setembro/dezembro de 2006. 
Hermenêutica do sujeito (2004b) e nos dois volumes finais da História da sexualidade (1997b, 1997c) tivesse voltado sua atenção à maneira com a qual o sujeito se constitui de forma ativa através das práticas de si fornecidas por esquemas sugeridos e propostos aos indivíduos para fixar sua identidade, mantê-la ou transformá-la como função de certo número de objetivos e através de relações de autodomínio e autoconhecimento, uma posição, como se nota, bem distinta da presente naqueles estudos nos quais Foucault procurava compreender, a partir dos mecanismos disciplinares e biopolíticos de controle da população, a genealogia do sujeito moderno enquanto objeto, dócil e útil. Como resultado dessa reviravolta, restaura-se o lugar de sujeitos no quadro da luta política: agora é preciso colocar o problema da vontade individual (FOUCAULT, 1999b).

Essas técnicas de si ou do eu, formas através das quais o sujeito se autoconstitui enquanto senhor de seus atos, poderiam ser caracterizadas como um exercício de si sobre si mesmo a partir do qual os indivíduos realizam um certo número de operações em seu corpo, em seus pensamentos, em suas condutas, procurando se transformar e atingir um certo modo de ser, fazendo de sua vida uma obra que seja portadora de certos valores estéticos e que corresponda a certos critérios de estilo cuja representação derive da escolha livre e razoável do próprio sujeito. É o que se poderia chamar, como Foucault (1997b, 1997c, 2004a, 2004b) o faz, de uma arte da existência ou de uma estética da existência: "Trabalho de si para consigo, elaboração de si para consigo, transformação progressiva de si para consigo em que se é o próprio responsável por um longo labor que é o da ascese (áskesis)".(FOUCAULT, 2004b, p. 20).

Ao contrário do que se possa imaginar de imediato, a atividade consagrada a si mesmo não constitui um exercício de solidão, mas um modo de viver junto, uma verdadeira prática social: não existe auto-estilização na solidão. $\mathrm{O}$ cuidado de si apresenta-se como uma verdadeira intensificação das relações sociais, já que o

Movimento, Porto Alegre, v.12, n. 03, p. 141-164, setembro/dezembro de 2006. 
governo de si implica necessariamente a relação com outros, integrando uma prática dos governos dos outros, pois nisso também reside a arte de governar (FOUCAULT, 1997c). Foucault sublinhará em várias passagens a necessidade desse vínculo intersubjetivo. São como duas vias de acesso inversas para uma mesma questão: “[...] como se constitui uma 'experiência' em que estão ligadas, a relação consigo mesmo e a relação com os outros" (FOUCAULT, 2004a, p. 242-243). É por isso que a racionalidade do governo dos outros é idêntica à racionalidade do governo de si próprio: para ser um bom governante é preciso primeiro governar a si próprio. Trata-se de uma condição pedagógica, ética, mas, também ontológica para a constituição de um bom governante: "[...] ocupar-se consigo para poder governar, e ocupar-se consigo na medida em que não se foi suficiente e convenientemente governado" (FOUCAULT, 2004b, p. 57).

Torna-se claro, desse modo, que essa inflexão foucaultiana em direção ao sujeito ativo que cuida de si próprio para cuidar mais bem dos outros não constitui para ele um declarado descompromisso político muito menos a celebração de um individualismo hedonista, mas, ao contrário, relaciona-se à sua aposta segundo o qual a resistência às formas dominantes do poder político na atualidade passa necessariamente pela relação de si para consigo. Isto significa que devemos considerar: "[...] que as relações de poder/governamentalidade/governo de si e dos outros/ relação de si para consigo compõem uma cadeia, uma trama e que é em torno destas noções que se pode, a meu ver, articular a questão da política e a questão da ética" (FOUCAULT, 2004b, p. 307). Trata-se para Foucault, então, não mais de uma leitura política em termos de dispositivo de poder político, mas uma leitura ética em termos de prática, de problematização e hermenêutica de si que permite aos indivíduos interrogarem-se sobre sua própria conduta, velar por ela, formá-la e subvertê-la, inventando, assim, novos modos de subjetivação, novos estilos de vida individual, mas também social, para além das objetivações impostas pelas tecnologias

Movimento, Porto Alegre, v.12, n. 03, p. 141-164, setembro/dezembro de 2006. 
de dominação do poder. Em suma, uma genealogia do sujeito como sujeito de ações éticas que determinariam a maneira pela qual o indivíduo deve se constituir a si mesmo como o sujeito moral de suas próprias ações.

Se o estudo do Ocidente moderno ocultara a Foucault a existência dessas técnicas de si, obscurecidas que estavam pelos sistemas de saber, dispositivos de poder e as técnicas de dominação por eles engendrados, de que maneira essa nova analítica do poder foucaultiana oferece ferramentas (FOUCAULT, 1992) para (re)pensar o comprometimento da agência pedagógica crítica com relações de poder cuja natureza transcende à produção de estados de dominação e controle dos sujeitos em direção a práticas autônomas de subjetivação?

\section{EM DEFESA DA EMANCIPAÇÃO E DAAUTONOMIANA PEDAGOGIA CRIITICA DA EDUCAÇÃO FÍSICA: DO ESPECTRO DA REGULAÇÃO E CONTROLE AO CUIDADO PARA NÃO SER EXCESSIVAMENTE GOVERNADO NAS RELAÇÕES DE PODER}

Se a história de um autor no país coincide com a história de sua recepção ${ }^{5}$, não seria absurdo afirmar que a história de Foucault no Brasil com a pedagogia crítica ficou bastante marcada em função de uma interpretação que privilegiou a denúncia às tecnologias de dominação e as práticas contra a liberdade engendradas no seio da escola. Se o poder e suas relações, como vimos, escapam ao espectro da dominação e da subjugação dos sujeitos, pressupondo a existência de indivíduos livres para que suas relações de força sejam exercidas, a ênfase foucaultiana nos processos de objetivação e sujeição dos indivíduos pelas tecnologias de saber/poder disciplinares e de governo biopolítico contribuiu para a proliferação de

${ }^{5}$ Devo esta observação ao professor Alexandre Fernandez Vaz.

Movimento, Porto Alegre, v.12, n. 03, p. 141-164, setembro/dezembro de 2006. 
uma série de mal-entendidos em educação física cujo resultado não foi outro senão a conclusão do caráter de assujeitamento das relações de poder nas escolas, que passaram a ser oncebidas como maquinarias disciplinares onde "[...] uma relação de fiscalização, definida e regulada, está inserida na essência da prática do ensino: não como uma peça trazida ou adjacente, mas como um mecanismo que lhe é inerente, e multiplica sua eficiência" (FOUCAULT, 1993, p. 158). A educação física foi entendida como mais um dos dispositivos de poder/saber centrais na tarefa de disciplinarização, regulação e governo das pessoas e das populações. É como se estivesse minada a priori qualquer possibilidade de uma relação pedagógica que escapasse à produção subjetiva do sempre igual e do sempre mesmo nas sociedades em acelerado processo de normalização, já que era prático e estrategicamente necessário constituir, sobre a base da escola, relações de poder-saber:

\section{[...] manifestas na disposição de agir para estruturar o campo possivel de ações de tal su- jeito. Fechando suas portas a todas as outras possibilidades, que não aquelas definidas pe- las relações de poder-saber atuantes na socie- dade ocidental adulta, machista, branca, hete- rossexual, burguesa, judaico-cristã, eurocêntrica, colonialista [...]. Até quando [o discurso educacional] continuará olhando para esses olhos de poder sobre o currículo, de ma- neira inocente? (CORAZZA, 2004, p. 54-55).}

Não separar regulação e saber foi a fórmula encontrada por aquelas perspectivas educacionais chamadas pós-críticas que compreendem o currículo, sem inocência, em sua relação com um campo de forças e com um campo de poder. As forças que o governam obedecem a um impulso pelo domínio, pela supremacia e pela superioridade uma vez que sua dinâmica é movida pelo desejo de dominar. Esse impulso ou essa ânsia para o controle chama-se vontade de poder: é ela "[...] que transforma o caos em ordem, a diferença em identidade, o movimento em permanência, o devir

Movimento, Porto Alegre, v.12, n. 03, p. 141-164, setembro/dezembro de 2006. 
em ser, a multiplicidade em unidade" (SILVA; CORAZZA, 2003, p. 48). O currículo, como expressão dessa vontade de poder, seria o local não apenas no qual se desdobraria essa vontade e as relações que engendra, mas encarnaria as relações de poder como sendo "[...] sempre uma imposição de sentidos, de valores, de saberes, de subjetividades particulares. É sempre uma escolha forçada, para nos valermos da força de um oxímoro" (SILVA; CORAZZA, 2003, p. 55).

Em evidente contraste com as pedagogias críticas, para quem a vinculação da educação com as relações de poder foi central na crítica ideológica da escola capitalista, as pedagogias pós-críticas não limitam a análise do poder ao campo das relações econômicas, do Estado e de seus aparelhos ideológicos. Todavia, apesar dessa necessária expansão no mapa do poder, ela ainda permanece presa a uma concepção do poder cuja produtividade é quase o sinônimo de dominação, já que:

[...] a análise da dinâmica de poder envolvida
nas relações de gênero, etnia, raça e sexuali-
dade nos fornece um mapa muito mais comple-
to e complexo das relações sociais de domina-
ção do que aquele que as teorias críticas, com
sua ênfase quase exclusiva na classe social.
(SILVA, 1999, p. 146).

Se as pedagogias pós-críticas, com sua concepção nominalista de poder de inspiração foucaultiana, nos ensinaram que o poder está por toda parte e é multiforme, então as pedagogias críticas não nos deixam esquecer, todavia, "[...] que algumas formas de poder são visivelmente mais perigosas e ameaçadoras do que outras" (SILVA, 1999, p. 147). Dessa periculosidade não escaparia nem mesmo os impulsos emancipadores e libertadores da pedagogia crítica, já que eles não estariam livres à vontade de domínio e controle (de poder, portanto) encarnado no currículo de toda pedagogia moderna (SILVA, 1999; LIMA, 1997b).

O elo das passagens acima não é outro senão a descrição por 
parte dos autores daquilo que seria para Foucault efeitos ou instrumentos do poder, já que sua positividade estaria relacionada à produção de posições de sujeito de um determinado tipo e não de outro, à regulação e controle da conduta dos educandos, produzindo sempre a identidade de todos ao poder da norma ao invés da diferença irredutível. Trata-se de uma leitura do poder que o evidencia apenas como domínio, como senhorio, único princípio explicativo ou lei necessária, mas não como campo de governo no qual reversibilidades e possíveis mudanças entram em cena, maneira pela qual os efeitos coercitivos de seu uso poderiam ser dissolvidos partindo-se exatamente da questão de não admitir ser governado. Portanto, se trata de dizer que o resultado das relações de poder não faz outra coisa que não coagir e obrigar. Não queremos dizer com isso que as escolas modernas, expressões que se tornaram das técnicas e táticas de individualização e normalização da governamentalização do Estado, não tenham se estruturado em função da estabilização das relações de poder no seu âmbito devido à prevalência das tecnologias de dominação. O que estamos chamando atenção é que a interpretação daqueles autores, contrariando uma sugestão do próprio Foucault, não se deu ao trabalho de distinguir, na denúncia da forma escolar moderna, entre jogos estratégicos de poder, estados de dominação e técnicas de governo, uma vez que a análise do poder centrou-se, à semelhança do que Foucault admitira em relação ao próprio trabalho, mormente nas técnicas e táticas de dominação que fizeram da produtividade das relações de poder na escola, única e exclusivamente, da ordem da disciplina e da formação de corpos e almas dóceis, sem ressaltar o espaço para o contra poder e para o desabrochar das práticas de liberdade presentes em toda e qualquer relação de poder. Como se vê, não se trata de negar a importância da instituição escolar na organização das relações de poder, mas sim analisá-las a partir das próprias relações de poder, não o inverso, como aqueles autores parecem fazer. Parece valer para eles a seguinte equação: poder legislador escolar de um lado, sujeito obediente de outro.

Movimento, Porto Alegre, v.12, n. 03, p. 141-164, setembro/dezembro de 2006. 
Indispostos com essa leitura que não consegue enxergar a positividade das relações de poder senão em seus instrumentos ou efeitos de dominação, Bracht e Almeida (2006) se questionaram pelas formas de ao menos se limitar ou evitar o impacto dominador do poder no ensino. Interessava-os saber, a partir dos escritos do sociólogo Zygmunt Bauman, como uma proposta pedagógica crítica poderia prescindir de seu caráter normativo em função do fato de se mover no interior de relações de poder, sem existir qualquer possibilidade de se colocar para além delas. Em termos foucaultianos, a Bracht e Almeida (2006) importavam discutir a presença das relações de poder na prática pedagógica crítica sem que seus jogos estratégicos entre liberdades fossem paralisados em função de sua estabilização em estados de dominação, obnubilando, assim, os impulsos emancipadores e libertadores presentes em uma proposta pedagógica crítica ${ }^{6}$.

O que Bracht e Almeida (2006) não puderam compreender naquele momento, especialmente pelo fato de estarem influenciados por aquela interpretação (pós-crítica) que concebe as relações de poder como disciplina e regulação dos alunos na escola, é que essa leitura do poder como tecnologia da dominação em sua natureza, que distorce e corrompe até mesmo a melhor das intenções e os atos benignos que elas desencadeiam, é insustentável se considerarmos o último domínio foucaultiano, já que neste, concebido como ação sobre uma ação (como da ordem do governo), o poder sempre pressupõe a possibilidade da resistência, pois se trata de

${ }^{6}$ Para Bracht e Almeida (2006), no que se aproximariam de Foucault, a emancipação não significa um processo de libertação dos sujeitos por um partido político emancipador ou por uma cie mia rigorosa, multo menos ainda pressuporia o retorno a uma teoria a prion do sujeito, mas sim o árduo trabalho de subjetivação, nunca finalizado, assumido pelos indivíduos capazes de optar e governar a si próprios. À pedagogia crítica restaria a tarefa de instrumentalização dos indivíduos para que possam exercer criticamente a tarefa de sua autoconstituição, dotando-os da capacidade de desvendar as muitas antinomias que se colocam a essa genuína potência de auto-afirmação (a liberdade positiva), não aquela representada pela sua liberdade de consumir os muitos produtos no supermercado das identidades, uma pseudoliberdade ou liberdade negativa.

Movimento, Porto Alegre, v.12, n. 03, p. 141-164, setembro/dezembro de 2006. 
uma relação estabelecida entre pessoas potencialmente livres. Que nunca se possa colocar fora das relações de poder/saber não significa que se está inteiramente capturado por suas estruturas de dominação. Em outras palavras, que a pedagogia crítica jamais possa colocar-se em uma situação de não-poder não significa necessariamente que seus impulsos libertadores e emancipadores se confundam com estados de dominação: se ela está sempre em suas malhas, participando de seu jogo, não significa que ela é seu prisioneiro. Não se deve admitir jamais uma forma incontornável de dominação ou o privilégio absoluto da lei, da norma, da disciplina, do governo, mas, ao contrário, entender que enquanto as relações de poder estiverem presentes em todas as relações humanas (aí incluídas as pedagógicas) teremos certeza de que nelas há pessoas potencialmente capazes de dizer não a qualquer abuso no uso do poder. Trata-se precisamente de não ver que as relações de poder são más em si mesmas, das quais precisaríamos nos libertar. O poder definitivamente não é o mal: compreendê-lo assim é desistir da liberdade, pois só há relações de poder onde há liberdade. Se seguirmos Foucault, sem as relações de poder, quer dizer, sem as táticas e estratégias de resistência e liberdade que elas engendram, o que resta é apenas estado de dominação, cujo excesso pode tornar a vida alheia destituída de valor sob o signo da pura violência, como no caso dos totalitarismos.

Imersos, pois, em relações de poder que são benéficas para ambos os lados da interação pedagógica, não seria mais o caso para a pedagogia crítica, como alguns de nós da educação física um dia chegaram a acreditar (e alguns ainda acreditam!), de dizer aos outros o que fazer, apontando-lhes a verdade e o caminho até ela. Se o professor impõe aos alunos sua verdade, está impedindo a estes a prática de sua liberdade na relação de poder. Acontece que essa humildade epistemológica e política - a admissão do caráter discursivo de toda aspiração à verdade de uma pedagogia crítica (BRACHT; ALMEIDA, 2006) - não nos liberaria, como intelectuais específicos (FOUCAULT, 1992) em luta contra os

Movimento, Porto Alegre, v.12, n. 03, p. 141-164, setembro/dezembro de 2006. 
abusos de poder dentro e fora da escola, da proposição de certas técnicas de governo, normativas par excellence, que ofereceriam aos educandos uma direção, sempre provisória e até segunda ordem, em busca de sua autonomia e liberdade. É por isso que o próprio Foucault (2004a, p. 284) não vê onde está o mal, “[...] na prática de alguém que, em um dado jogo de verdade, sabendo mais do que um outro lhe diz o que é preciso fazer, ensina-lhe, transmite-lhe um saber, comunica-lhe técnicas [...]”. Nada provaria de antemão para Foucault que, em uma dada relação pedagógica, quer dizer, em uma situação no qual aquele que sabe mais governa a ação daquele que sabe menos, a autogestão produziria os melhores resultados. Foucault pensa que, diante dessa ambigüidade, precisamos observar todos os detalhes, sendo ao mesmo tempo extremamente prudentes e empíricos: só no seu exercício se pode decidir se a relação de poder é boa ou ruim. Essa é uma proposição bem diferente da tendência de se conceber um projeto formativo que, em função de seu envolvimento com relações de poder que supostamente só fizeram padecer sob o signo da identidade tudo aquilo que é diferente, fosse concebido sem ter uma idéia prescritiva de seu desenvolvimento nem qualquer modelo normativo de sua realização. Algo assim como "[...] um devir plural e criativo, sem padrão e sem projeto, sem uma idéia prescritiva de seu percurso e sem uma idéia normativa, autoritária e excludente de seu resultado [...]". (LARROSA, 2002).

Contrariamente àqueles que desconfiam das pretensões de uma pedagogia que ambiciona a autonomia e emancipação dos sujeitos (SILVA, 1999; SILVA; CORAZZA, 2003; LIMA, 1997a, 1997b), já que ela, além de supostamente reintroduzir pela porta dos fundos a fantasia de um sujeito soberano no pleno comando de seus atos, não escaparia às relações de controle, disciplina e dominação dos alunos envolvidos na prática pedagógica (e da vontade que poder que ela encarna), não se trataria de defender, se seguirmos Foucault (1999b), a afirmação contrária na contraposição à governamentalização presente no ato pedagógico (sua normatividade): não permitir ser governado de forma alguma (ne-

Movimento, Porto Alegre, v.12, n. 03, p. 141-164, setembro/dezembro de 2006. 
nhum forma de governamentalidade), mas antes “[...] como não ser governados deste modo, em nome destes princípios, em vista de tais objetivos e através de tais procedimentos" (FOUCAULT, 1999b, p. 2). A atitude crítica para ele caracterizar-se-ia exatamente pelo desenvolvimento da arte de não ser excessivamente governado, opondo com a liberdade da palavra do governado "[...] direitos universais e imprescritíveis aos quais qualquer governo, tratando-se tanto do monarca, como do magistrado, do educador, do pai de família, deverá submeter-se" (FOUCAULT, 1999b, p. 3). Não querer ser governado de uma maneira específica, recusar aquilo que querem que sejamos, implica "[...] não aceitar como verdadeiro o que uma autoridade sustenta ser verdadeiro, mas só se forem considerados, em plena autonomia, como boas, as razões para o aceitar" (FOUCAULT, 1999b, p. 3). A crítica, dessa maneira, designaria o movimento através do qual o:

[...] sujeito reconhece ter o direito de interrogar a verdade nos seus efeitos de poder e o poder nos seus discursos de verdade; a crítica será, portanto, a arte da desobediência voluntária, da indocilidade raciocinada. Função fundamental da crítica seria, por isso, o dessubjugamento (des-sujeitamento) no jogo que se poderia denominar a política da verdade (FOUCAULT, 1999b, p. 3).?

O problema que se apresentaria a Foucault na relação pedagógica seria possibilitar o uso livre das estratégias e jogos de poder, buscando:

[...] saber como será possivel evitar nessas práticas - nas quais o poder não pode deixar de ser exercido e não é ruim em si mesmo - os efeitos de dominação que farão com que um

${ }^{7}$ A tradução da obra de Foucault, em italiano, lluminismo e crítica. Roma: Donzelli Editore, 1999b, foi realizada por Selvino José Assmann.

Movimento, Porto Alegre, v.12, n. 03, p. 141-164, setembro/dezembro de 2006. 
garoto seja submetido à autoridade arbitrária e inútil de um professor primário; um estudante, à tutela de um professor autoritário etc. (FOUCAULT, 2004a, p. 284-285).

Como não borrar então a tênue fronteira existente entre a mão que acaricia o rosto do outro e aquela que o oprime? Como estabelecer o limite entre a dominação sobre o outro e um exercício que poder que pressuponha prática de liberdade na relação pedagógica? O professor que tomasse para si a tarefa de não governar excessivamente seria precisamente aquele que, ao exercer suas técnicas de governo sobre os outros, é capaz de exercer ao mesmo tempo seu poder sobre si, já que somente aquele que cuida de si não será escravo de seus desejos e verdades, impondo-as aos outros. O governo dos outros na prática pedagógica passaria, em primeiro lugar, pelo governo de si próprio, já que é essa autocrítica daquilo que ele faz a si mesmo quem vai regular o poder do professor sobre os outros, seus alunos. Assim concebido, o cuidado de si apareceria como uma conversão ao poder, ou seja, uma forma de controlá-lo. Seria preciso, portanto, que as relações de poder no trato pedagógico se desenrolassem com o mínimo possível de dominação graças ao recurso à regras de direito, a técnicas racionais de governo e de ethos, de práticas de si e de liberdade, já que o ponto de articulação entre "[...] a preocupação ética e a luta política pelo respeito dos direitos, entre a reflexão crítica contra as técnicas abusivas de governo e a investigação ética [é o] que permite instituir a liberdade individual". (FOUCAULT, 2004 p. 285).

A batalha que se travaria para não ser excessivamente governado nem governar em excesso é o desafio para resistir à condição de minoridade em nossos dias, quer dizer, uma vida desvinculada de guias, tutores e autoridades que controlariam a esfera subjetiva e o mundo social, algo muito próximo àquilo que Kant definia como Aufklärung. O topo ao qual se poderia chegar através da prática refletida dessa luta pela liberdade seria o autogoverno dos indivíduos livres e autônomos (portanto, emancipados) na relação que estabelecem consigo próprio e com os outros. Nesse caso,

Movimento, Porto Alegre, v.12, n. 03, p. 141-164, setembro/dezembro de 2006. 
caberia à pedagogia crítica concebida como contrapoder, como conversão do poder, fomentar ad infinitum a liberdade, a mobilidade e a reversibilidade dos jogos de poder presentes na relação pedagógica, condições não só para a resistência aos estados de dominação nela em jogo, mas também da própria possibilidade de criação de novas formas de subjetividade em trabalho perpétuo de re-elaboração de si própria, escapando assim às práticas de individualização e totalização impostas não tanto hoje pela governamentalização estatal, mas, sobretudo, pela neoliberal.

Se for incontestável que as Luzes que descobriram a liberdade também inventaram a disciplina (FOUCAULT, 1993), também o é o fato que se deve ao Aufklärung, como idade da crítica, a gênese de um novo ethos filosófico (ou atitude de crítica permanente de nosso ser histórico) em relação ao presente e à constituição de nós mesmos como sujeitos autônomos (FOUCAULT, 2000) ${ }^{8}$. À semelhança do exercício autocrítico empreendido por Bracht e Almeida (2006), só que guiados pelos passos da ontologia crítica de nós mesmos, nesse artigo houve o firme propósito de continuar se perguntando pelo sendo da pedagogia crítica na educação física e seguir problematizando sua própria atualidade discursiva. A esperança é que esse esforço de autocrítica nos possibilite, mesmo reconhecendo os limites do que é necessário, continuar apostando no papel que a pedagogia crítica tem ainda a desempenhar no sentido de fazer com que os excessos de poder em tempos incertos e ambivalentes como o nosso sejam convertidos cada vez mais em direções democráticas e progressistas.

${ }^{8}$ É digno de nota registrarmos o respeito com que Foucault (2000) refere-se ao Aufklärung, nos convidando a escapar à chantagem intelectual e política de estar contra ou a seu favor. Ao manter-se na fronteira, estabelecendo uma relação ambígua em relação a ele, sua ontologia crítica orienta-se para os limites da necessária tradição filosófica inaugurada pelo próprio Aufklärung, quer dizer, uma reflexão orientada até o que já não é indispensável para a constituição de nós mesmos como sujeitos históricos. Um trabalho sobre nossos limites, quer dizer, um exercício paciente que dê forma à impaciência da liberdade. Essa é uma posição bem distinta daquela tomada por autores do campo educacional que ao apontarem os limites da pedagogia crítica moldada à maneira da modernidade, jogam fora, por assim dizer, a criança com toda a água do banho.

Movimento, Porto Alegre, v.12, n. 03, p. 141-164, setembro/dezembro de 2006. 


\section{Critical Pedagogy of Physical Education in the} Power-Relations Game

Abstract: This article is part of a research on the foundations of the critical pedagogy of Physical Education. It chooses for the dialogue the philosopher Michel Foucault's writings, to investigate the self realignment in his discussion about the notion of (relation of) power and subject in the last domain of his work. It tries to understand the corollary of this displacement in the emancipators liberators pulses and of Critical Pedagogy in Physical Education. It points the urgency of permanent self-critical analysis of its discursive actuality.

Keywords: Physical Education. Power. Social control, informal. Michel Foucault.

Pedagogía Crítica de la Educación Física en el juego de las Relaciones de Poder

Resumen: Este texto es parte de una investigación sobre los fundamentos de la Pedagogía Crítica de la Educación Física. Elige como interlocutor los escritos del filósofo Michel Foucault, preguntando por la reordenación que hace en su discusión sobre la noción de (relaciones de) poder y sujeto en el último dominio de su obra. Busca comprender los corolarios de este desplazamiento en los impulses emancipadores y libertadores de la pedagogía crítica en nuestra área. Apunta para la urgencia de seguir reflexionando de manera autocrítica sobre su propia actividad discursiva.

Palabras clave: Educación física. Poder. Controle informales de la sociedad. Michel Foucault. 


\section{REFERÊNCIAS}

BRACHT, V.; ALMEIDA, F. Q. Emancipação e diferença na educação: uma leitura com Bauman. São Paulo: Autores Associados, 2006.

CORAZZA, S. M. O que quer o currículo: pesquisas pós-críticas em educação. Petrópolis: editora Vozes, 2004

FOUCAULT, M. Microfísica do poder. Rio de Janeiro: Graal, 1992. 1993

Vigiar e punir: história da violência nas prisões. Rio de Janeiro: Vozes,

. O sujeito e o poder. In: DREYFUS, H.; RABINOW, P. (Org.). Michel Foucault. Uma trajetória filosófica: para além do estruturalismo e da hermenêutica. Rio de Janeiro: Forense universitária, 1995. p. 231-249.

$\overline{1997 a}$

História da sexualidade I: a vontade de saber. Rio de Janeiro: Graal

História da sexualidade II: o uso dos prazeres. Rio de Janeiro: Graal, $997 b$

História da sexualidade III: o cuidado de si. Rio de Janeiro: Graal, 1997c.

Em defesa da sociedade. São Paulo: Martins Fontes, 1999a.

Iluminismo e crítica. Roma: Donzelli Editore, 1999b.

Ditos e escritos: Arqueologia das ciências humanas e história dos sistemas de pensamento. Rio de Janeiro: Forense Universitária, 2000. v.2.

Ditos e escritos. Estratégia, poder-saber. Rio de Janeiro: Forense Universitária, 2003. v. 4.

Ditos e escritos. Ética, sexualidade, política. Rio de Janeiro: Forense Universitária, 2004a. v. 5

A hermenêutica do sujeito: São Paulo: Martins Fontes, 2004b.

GROS, F. Situação do curso. In: FOUCAULT, M. A hermenêutica do sujeito. São Paulo: Martins Fontes, 2004. p. 613-661.

LARROSA, J. Literatura, experiência e formação. In: COSTA, M. V. (Org.) Caminhos investigativos: novos olhares na pesquisa em educação. Rio de Janeiro: DP\&A, 2002. p. 133-160.

LAZZARATO, M.. Del bipoder a la biopolítica. Multitudes: Revue trimestrielle, politique, artistique et culturelle, mar. 2000. Disponível em: http:// multitudes.samizdat.net/Del-biopoder-a-la-biopolitica.html>. Acessado em: 15 maio 2006 .

Movimento, Porto Alegre, v.12, n. 03, p. 141-164, setembro/dezembro de 2006. 
LIMA, H. L. A. O adeus à Educação Física progressista. In: CONGRESSO BRASILEIRO DE CIÊNCIAS DE ESPORTE, 10, 1997, Goiás. Anais... Goiás: Colégio Brasileiro de Ciências do Esporte, v.1. 1997a. p. 83-88.

O campo acadêmico da Educação Física face ao esgotamento das pedagogias radicais. In: CONGRESSO BRASILEIRO DE CIÊNCIAS DO ESPORTE, 10, 1997b, Goiás. Anais... Goiás: Colégio Brasileiro de Ciências do Esporte, v. 2. 1997b. p. 1611-1615.

MORAES, M. C. M. O renovado conservadorismo da agenda pós-moderna. Cadernos de Pesquisa, Campinas, v. 34, n. 122, p. 337-357, maio/ago. 2004.

NOGUEIRA, Q. W. C. Genealogia da Educação Física crítica: estudo dos saberes e práticas pedagógicas da perspectiva crítica em Educação Física. 2004. 147f. Dissertação (Mestrado em Educação) - Programa de Pós-Graduação em Educação, Universidade Federal de Uberlândia, Uberlândia, 2004.

ORTEGA, F. Amizade e estética da existência em Foucault. Rio de Janeiro: Graal, 1999.

PARAíSO, M. A. Pesquisas pós-críticas em educação: esboço de um mapa Cadernos de Pesquisa, Campinas, v. 34, n. 122, p. 283-303, maio/ago. 2004.

SENELART, M. A crítica da razão governamental em Michel Foucault. Tempo social: Revista de Sociologia da USP. São Paulo, v. 7, n. 1-2, p. 1-14, 1995.

SILVA, T. T. Documentos de identidade: uma introdução às teorias do currículo. Belo Horizonte: Autêntica, 1999.

SILVA, T. T.; CORAZZA, S. M. Composições. Belo Horizonte: Autêntica, 2003.

VEIGA-NETO, A. Foucault e educação. Belo Horizonte: Autêntica, 2003. 